\title{
Adjuvant Therapy of Breast Cancer: Can We Do Better?
}

\author{
Christoph Thomssen ${ }^{\mathrm{a}}$ Wolfgang Janni ${ }^{\mathrm{b}}$ \\ a Universitätsklinik und Poliklinik für Gynäkologie, Halle (Saale), \\ ${ }^{b}$ Frauenklinik, Universitätsklinikum Düsseldorf, Heinrich-Heine-Universität, Düsseldorf, Germany
}

In this issue of BREAST CARE the expert discussion focuses on adjuvant treatment of early breast cancer. This discussion deals with the subject on a rather high level. Considering the substantial reductions of risk of recurrence and death that we have achieved today, the following questions arise: How good are we? Can we talk about potential cure of breast cancer? Are we good enough? Can we do better? Are there limits? What are the limits?

\section{How Good Are We?}

The Oxford overview [1] calculated a relative reduction of mortality of $45-57 \%$ over 15 years of follow-up, just by the 'old standard' therapeutics as 3-drug anthracycline-based combinations and tamoxifen. The effect was higher in younger, premenopausal than in older, postmenopausal patients. These results were achieved without the use of modern therapy modalities, such as taxanes, dose-dense chemotherapy, trastuzumab, aromatase inhibitors, ovarian suppression, and bisphosphonates. Also, the survival effect of screening and radiotherapy was not included in this estimation.

In San Antonio 2007, Sir Richard Peto [2] calculated that by administering taxane-containing regimens, the overall mortality in breast cancer patients can be reduced by $34 \%$ (in women 50-69 years of age) to 54\% (in women younger than 50) in comparison to untreated controls (without adjuvant chemotherapy). Adding the effects of tamoxifen, this may result at a total relative risk reduction of $54-68 \%$. Trastuzumab in patients with HER2 overexpressing tumors may reduce mortality by another third, additional effects may be expected by the use of bisphosphonates, aromatase inhibitors, and radiotherapy. Overall, in some patients the relative reduction of the risk to die from breast cancer may reach 70 or $80 \%$, if all available adjuvant therapy modalities are adequately used. Thus, even in node-positive patients the risk to die from the breast cancer is lower than $15 \%$. - In summary, considering these figures, we are quite good.

\section{Can We Talk About Cure?}

Our answer is yes and no. 'Yes', we can talk about curable disease in some cases. A 60-year-old woman diagnosed with steroid receptor-positive HER2 overexpressing breast cancer, today has a high probability to reach her 80th year of life. So, in this group of patients, we can realistically talk of a good chance to be cured.

But also 'No', we cannot talk about a curable disease. There are still patients who have an unfavorable prognosis. A 44-year-old patient with a basal-like tumor, that does not regress well on aggressive neoadjuvant chemotherapy still has a high probability to die early from metastatic breast cancer. Although some new drugs are in development (e.g. PARP-inhibitors), currently we do not have good measures to change the fate of these patients. Here are still limits.

\section{But How Can We Do Better?}

Because we don't want to miss a potential chance of cure, we tend to recommend adjuvant treatment, if we calculate a reasonable absolute benefit from treatment. What does 'reasonable' mean? The mean overall absolute benefit from either endocrine or chemotherapy versus no therapy are estimated to be about $10-15 \%$. However, in high-risk patients (e.g. nodepositive), this absolute reduction of risk will be higher, while in low-risk patients these effects are much lower, resulting in substantial overtreatment and unnecessary reduction of quality of life.

A solution to this problem seems to be improved prognostic information on the natural course of disease and particularly better prediction of the effect of a specific therapy. To date, nodal status, grading of malignancy and the invasion factors uPA/PAI-1 are well established as strong and independent prognostic factors. Estrogen receptor (ER) status and HER2 status give us additional predictive information about potential effects of chemotherapy, endocrine therapy and trastuzumab. Other factors like proliferation, genomic, proteomic, or

\section{KARGER}

Fax +49 7614520714

Information@Karger.de

www.karger.com (c) 2009 S. Karger GmbH, Freiburg

Accessible online at:

www.karger.com/brc
Prof. Dr. med. Christoph Thomssen

Universitätsklinik und Poliklinik für Gynäkologie

Martin-Luther-Universität Halle-Wittenberg

Ernst-Grube-Str. 40, 06097 Halle (Saale), Germany

Tel. +49 345 557-1847, Fax -1501

christoph.thomssen@medizin.uni-halle.de 
methylation profiling are still considered to be experimental, having shown their impact only in retrospective, but not in prospective trials.

In the near future, new techniques may be validated and available for routine testing. Early studies of gene expression profiling techniques $[3,4]$ showed that tumors can be better characterized and classified into new categories (luminal-type, HER2-type, and basal-type breast cancer). Genomic grading [5] and genomic profiling $[6,7]$ may also lead to better prognostic and predictive information. Particularly in ER-positive disease, adjuvant chemotherapy then may be better confined to those patients who really benefit from it.

A relatively new approach is the analysis of the specific drug action in individual patients. First results suggest that drugs, which are administered as less active pro-drug are not always metabolized to its active form in a sufficient manner. In case of enzyme polymorphism, active metabolites may be present in lower concentrations, resulting in a less than expected activity of the drug. This phenomenon has been demonstrated for tamoxifen, but it is reasonable to expect such variations also for other drugs. In addition, some drugs show variations of their activity dependent on the co-medication. Such effects have been shown for 5-fluorouracil and methotrexate, but also for modern tyrosine kinase inhibitors. So in future, not only increased information about the tumor, but also information about its host and the drugs themselves may help to individualize therapy.
Individualization of therapy should also consider the shortand long-term side effects of the individual compound delivered. Particularly cardiac side effects, skin toxicity, peripheral and central neurotoxicity, as well as gastrointestinal toxicity, but also the risk of therapy-induced malignancies is getting into the focus of interest. For example, patients with heart diseases will preferentially be treated without anthracyclines and in patients who's daily life / profession depends on fine motor skills neurotoxic drugs should be left out. Research has to concentrate on prediction and prophylaxis of side effects, such that unnecessary risks can be avoided. Two major phase III trials in Germany currently prospectively evaluate the heavily debated efficacy of anthracyclines in HER2-positive patients (Plan B and SUCCESS C), and also include extensive translational research programs, comprising minimal residual disease surveillance, testing for single nucleotide polymorphisms, uPA/PAI-I testing and prospective evaluation of gene profiles.

\section{We Are Good, but We Can Do Better!}

In summary, we are good, but we can do better! Not only by increasing the efficacy of specific drugs, but also by more intelligent individualization of the adjuvant approach in order to avoid overtreatment and unnecessary side effects. More and subtle knowledge about the properties of tumor, drugs and the patient herself is the prerequisite.

And if we cannot decide, because data are too weak? Then expert discussions must help to find the best way by outweighing the pros and cons of each modality.

\section{References}

1 Early Breast Cancer Trialists' Collaborative Group (EBCTCG): Effects of chemotherapy and hormonal therapy for early breast cancer on recurrence and 15-year survival: an overview of the randomised trials. Lancet 2005;365:1687-1717.

2 Peto R, for the Early Breast Cancer Trialists' Collaborative Group: The worldwide overview: new results for systemic adjuvant therapies. San Antonio Breast Cancer Symposium 2007, P-1.

$\checkmark 3$ Perou CM, Sørlie T, Eisen MB, van de Rijn M, Jeffrey SS, Rees CA, Pollack JR, Ross DT, Johnsen $\mathrm{H}$, Akslen LA, Fluge O, Pergamenschikov A, Williams C, Zhu SX, Lønning PE, Børresen-Dale AL, Brown PO, Botstein D: Molecular portraits of human breast tumours. Nature 2000;406:747-752.
4 Sørlie T, Perou CM, Tibshirani R, Aas T, Geisler S, Johnsen H, Hastie T, Eisen MB, van de Rijn M, Jeffrey SS, Thorsen T, Quist H, Matese JC, Brown PO, Botstein D, Eystein Lønning P, Børresen-Dale AL: Gene expression patterns of breast carcinomas distinguish tumor subclasses with clinical implications. Proc Natl Acad Sci U S A 2001;98:10869-10874.

5 Sotiriou C, Wirapati P, Loi S, Harris A, Fox S, Smeds J, Nordgren H, Farmer P, Praz V, HaibeKains B, Desmedt C, Larsimont D, Cardoso F, Peterse H, Nuyten D, Buyse M, Van de Vijver MJ, Bergh J, Piccart M, Delorenzi M: Gene expression profiling in breast cancer: understanding the molecular basis of histologic grade to improve prognosis. J Natl Cancer Inst 2006;98:262-272.
6 van't Veer LJ, Dai H, van de Vijver MJ, He YD, Hart AA, Mao M, Peterse HL, van der Kooy K, Marton MJ, Witteveen AT, Schreiber GJ, Kerkhoven RM, Roberts C, Linsley PS, Bernards R, Friend SH: Gene expression profiling predicts clinical outcome of breast cancer. Nature 2002;415: 530-536.

7 Paik S, Shak S, Tang G, Kim C, Baker J, Cronin M, Baehner FL, Walker MG, Watson D, Park T, Hiller W, Fisher ER, Wickerham DL, Bryant J, Wolmark N: A multigene assay to predict recurrence of tamoxifen-treated, node-negative breast cancer. N Engl J Med 2004;351:2817-2826. 